\title{
Rare capecitabine-induced acute hypertriglyceridemia with angina: a case report and review of the literature
}

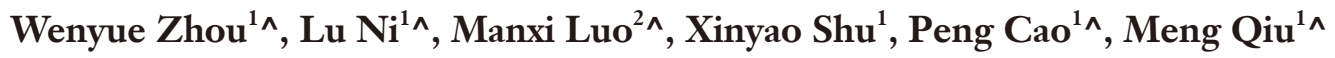 \\ ${ }^{1}$ Department of Oncology, West China Hospital, Sichuan University, Chengdu, China; ${ }^{2}$ Faculty of Medicine, University of New South Wales, \\ Sydney, Australia \\ Correspondence to: Meng Qiu, PhD. Department of Oncology, Cancer Center, West China Hospital, Sichuan University, Chengdu 610041, China. \\ Email: qiumeng33@hotmail.com.
}

\begin{abstract}
Capecitabine (CAP) is widely used to treat gastrointestinal and breast cancer, and is generally well tolerated. Hand-foot syndrome and gastrointestinal intolerance are the most common adverse effects. Capecitabine-induced hypertriglyceridemia (CIHT) is a very rare adverse effect and, from the reported literatures, is often neglected in clinical practice. Here, we report a case of CIHT with angina. A 58-year-old man with metastatic rectal cancer was admitted to the emergency room (ER) due to severe chest pain after treatment with CAP (Xeloda). The blood sample showed separation of blood and lipids, and the lipid profile revealed rapidly increased triglyceride and cholesterol levels. After fenofibrate therapy was administered, the patient's symptoms were relieved, and the repeat lipid test was normalized. Other causes of hyperlipidemia were carefully excluded, considering that the severe adverse effects of CAP had since abated. The earliest onset of the incidence as far as we know, the symptom of angina at the same time with CIHT, and distinct blood-lipid layer in blood sample all suggest the rarity of this case. We also concluded reports of CIHT and found that CIHT accidence was higher than our known. We genuinely hope that this case could awaken clinicians' awareness of the use of CAP.
\end{abstract}

Keywords: Hypertriglyceridemia; capecitabine (CAP); adverse drug effects; cardiotoxicity; case report

Submitted May 03, 2021. Accepted for publication Jul 22, 2021.

doi: 10.21037/apm-21-1109

View this article at: https://dx.doi.org/10.21037/apm-21-1109

\section{Introduction}

Capecitabine (CAP) (Xeloda) is an orally administered drug that can be metabolised into 5'-deoxy-5-fluorocytidine in tumor cells (1). This drug has been proven to have similar efficacy to 5 -fluorouracil with fewer unwanted adverse effects (2), CAP has been wildly used in the treatment of various tumors, including gastrointestinal tract, breast, pancreatic and biliary cancer. The main adverse reactions to CAP are gastrointestinal toxicity and hand-foot syndrome, and hypertriglyceridemia is rarely reported (3). Moreover, CAP-induced cardiotoxicity, such as that induced by fluorouracil, has been receiving increasing attention, as it commonly manifests with symptoms such as angina and arrhythmia. Coronary spasms and direct myocardial injury have been accepted as the main causes of CAP-associated cardiotoxicity (4), and no hypertriglyceridemia-related cases have yet been reported. To the best of our knowledge, this is the first case of CAP-induced hypertriglyceridemia (CIHT) presenting as angina. We present the following article in accordance with the CARE reporting checklist (available at https://apm. amegroups.com/article/view/10.21037/apm-21-1109/rc).

\footnotetext{
^ ORCID: Wenyue Zhou, 0000-0003-2100-9533; Lu Ni, 0000-0001-5673-6592; Manxi Luo, 0000-0003-2666-959X; Peng Cao, 0000-0003-0864-8998; Meng Qiu, 0000-0003-3722-6938.
} 


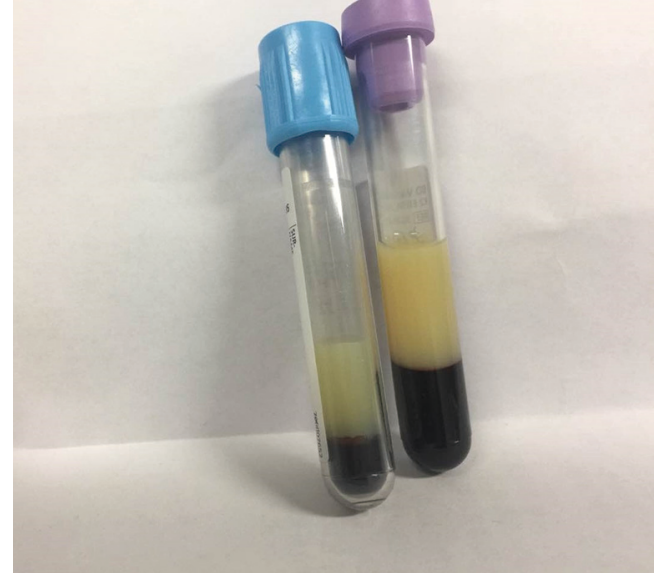

Figure 1 Onset blood samples of the patient showed layered lipids and blood.

\section{Case presentation}

A 58-year-old colorectal cancer patient was admitted to the emergency room (ER) of West China Hospital for acute retrosternal pain on March 22, 2017. Although he had no history of cardiac disorders, the ER doctor suspected angina because physical examination revealed radiating pain in his left shoulder and jaw. The patient subsequently underwent coronary angiography, myocardial enzymogram, and electrocardiogram, which showed no signs of myocardial infarction. Meanwhile, blood sample analysis showed distinct separation of lipids (Figure 1), with instant triglyceride $1,925.51 \mathrm{mg} / \mathrm{dL}$ (normal range, 25.69 to $162.08 \mathrm{mg} / \mathrm{dL}$ ), cholesterol $679.33 \mathrm{mg} / \mathrm{dL}$ (normal range, 248.00 to $504.85 \mathrm{mg} / \mathrm{dL}$ ).

After multidisciplinary consultation, we considered CAP-associated coronary spasm as the main cause of chest pain, given the proven cardiotoxicity of this drug (5), with the facilitation of hypertriglyceridemia. Pancreatitis was not considered because dynamic monitoring showed that his amylase, lipase, and blood calcium levels were within the normal range. The patient did not suffer from physical or emotional stressors; all biomarkers, including creatine kinase- $\mathrm{MB}$, troponin, and brain natriuretic peptide (BNP) did not suggest myocardial injuries, thus, Takotsubo was also excluded (6). The next day, his fasting blood test showed the level of lipid indexes reached peaks as triglycerides in $1,999.02(\mathrm{mg} / \mathrm{dL})$ and cholesterol at $797.13 \mathrm{mg} / \mathrm{dL}$ (Figure 2). After fenofibrate $200 \mathrm{mg}$ daily was added to the regimen, his blood triglyceride and cholesterol levels markedly decreased to 50.22 and $66.06 \mathrm{mg} / \mathrm{dL}$, respectively,



Figure 2 Triglycerides value changes of the patients before and after CIHT. CIHT, capecitabine-induced hypertriglyceridemia.

within a week.

The patient had a medical history of metastatic rectal cancer and had received rectum and metachronous lung metastasis resection. Considering that he had never received chemotherapy or refused infusion, adjuvant chemotherapy including single CAP (Xeloda) was administered at a moderate dose of $1,500 \mathrm{mg}$ twice a day, for 14 days, repeated every 3 weeks.

On the 13th day of the first chemotherapy cycle, the patient experienced chest pain. Before the onset of thoracalgia, the patient was in good condition (PS score 0 , with body mass index 24.2), and had no history of diabetes or cardiovascular diseases (CVD). The patient showed no liver or renal dysfunction, and no significant abnormalities were observed in the blood cell test before or after chemotherapy. In addition, no diet change (highfat or high-sugar diet), excessive drinking, or other inciting medications were used. His baseline fasting blood triglycerides was slightly increased $(179.80 \mathrm{mg} / \mathrm{dL}$, normal range from 25.69 to $162.08 \mathrm{mg} / \mathrm{dL}$ ), cholesterol was $360.87 \mathrm{mg} / \mathrm{dL}$ (normal range from 248.00 to $504.85 \mathrm{mg} / \mathrm{dL}$ ), and all other lipid markers were normal.

After reviewing the literature and consulting with endocrinologists and cardiologists, we carefully excluded other causes and considered that CIHT had contributed to the unexpected cardiotoxicity. The patient scored 5 points in both the Naranjo score (7) and the ALDEN score (8), which further suggested that CAP could account for the incident. The patient subsequently underwent total exon genome detection of blood, but no known genes involved in lipid metabolism disorder were observed. The patient was then withdrawn from chemotherapy and was regularly 


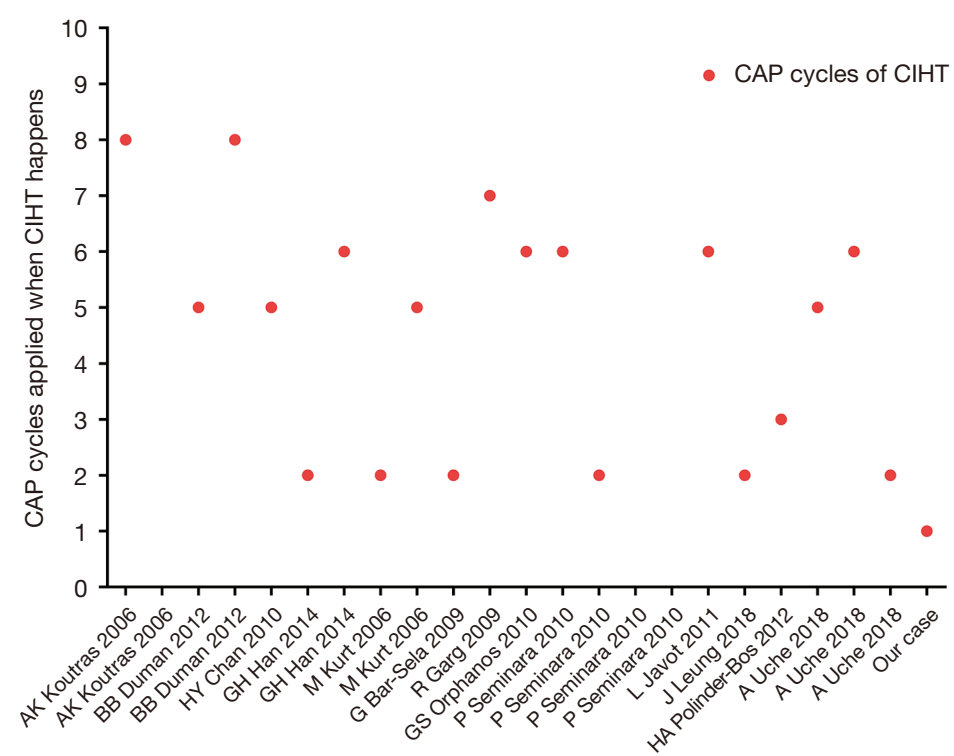

Figure 3 CAP appliance cycles when CIHT happens extracted from accessible case reports. CAP, capecitabine; CIHT, capecitabine-induced hypertriglyceridemia.

followed up with long-term blood tests and CT scans. Until now, the patient has survived without any tumor recurrence, and no cardiac distress or hypertriglyceridemia has been observed. All procedures performed in this study were in accordance with the ethical standards of the institutional and/or national research committee(s) and with the Helsinki Declaration (as revised in 2013). Written informed consent was obtained from the patient for publication of this case report and accompanying images. A copy of the written consent is available for review by the editorial office of this journal.

\section{Discussion}

To the best of our knowledge, this is the first case of CIHT with early onset and severe symptoms. We understand that the case would be more complete if the same symptom and high triglyceride levels occur again after reusing CAP; however, given the cardiovascular damage caused to the patient by the first use of the drug, for ethical reasons, he was permanently withdrawn from the treatment. According to the 2016 EAS consensus, hypertriglyceridemia is defined as TGs $>1.7 \mathrm{mmol} / \mathrm{L}$ or $150 \mathrm{mg} / \mathrm{dL}$ (9), hypertriglyceridemia is strongly related to metabolic disorders such as diabetes mellitus or hypothyroidism. Unhealthy lifestyles such as a high-fat diet, alcohol abuse, and obesity also play an important role (10). In addition, drug-induced hypertriglyceridemia is an often neglected factor. However, hypertriglyceridemia management guidelines suggest that hormone and immunosuppressive drugs such as oral estrogen, cyclosporin, beta-blockers, and thiazide-induced hypertriglyceridemia are not uncommon. Anti-tumor drug-induced hypertriglyceridemia is usually related to estrogen receptor modulators and aromatase inhibitors such as tamoxifen and letrozole, but chemotherapy-induced hypertriglyceridemia, especially CIHT, has rarely been reported.

In a literature review, we found 14 CIHT case reports, describing 22 patients in total, with one prospective related study. The median age was 54 years, and 10 of the 22 patients were male. All patients were diagnosed with colorectal or breast cancer. Five patients, including our case, were overweight (body mass index $>24)(11-15)$, five had hypertension (11-13,16), four had diabetes mellitus $(11,12,17,18)$, one patient was admitted to a high-fat diet (19), and one patient had a family history of hyperlipidemia (13). All patients received CAP-based regimens, and no monotherapy was administered.

According to the literature, the occurrence time of CIHT varied in each case (Figure 3); from the second cycle after the initiation of CAP to the ninth cycle, the median number of CAP cycles was 5 . To our knowledge, the onset time of our patients was the earliest, and may be related to the occurrence of cardiac symptoms, leading to early 
detection of blood lipids. According to CTCAE version 4.0, most patients, including ours, had grade 3 or 4 incidents (12-15,17-22). The main elevated blood lipid index was triglycerides, and elevated cholesterol levels can be observed in most cases. Statins and fibrates, and occasionally omega-3 fatty acid, were also used to treat dyslipidemia, and achieved good effects in decreasing lipid profile, which is also the reason why most patients were not withdrawn from CAP $(12,15,17,19,21-23)$.

Most of the reports describe simple hypertriglyceridemia without symptoms, while Garg et al. and Han et al. reported two cases of patients who developed hyperglycemia and CIHT simultaneously $(21,23)$, which may be explained by the fact that CAP could increase insulin resistance (13). Chan et al. reported a case of pancreatitis induced by CIHT (17). Finally, to our knowledge, this is the first known case of CIHT and angina, with the shortest time after CAP administration.

CIHT is often neglected because of its rarity, and the underlying mechanism is thus still unclear. Michie et al. found that diabetic patients or those with normal or moderately increased baseline TG levels are more likely to have higher TG levels (20). Some researchers have speculated that CAP could reduce the activity of lipases such as hepatic triglyceride lipase $(13,24)$. In patients whose hepatic lipase activity was low or lacking, triglycerides accumulated, resulting in the occurrence of CIHT. Seminara et al. monitored TG level changes in 38 colorectal and breast cancer patients treated with a CAP-based regimen, and CIHT was observed in four patients (14). In a prospective study, Michie et al. found that the occurrence of CIHT is approximately $3.7 \%$, and is sufficient to be classified as a "common" adverse drug effect. In their study, patients did not receive CAP monotherapy for ethical considerations; however, as the authors explained, neither oxaliplatin monotherapy nor the FOLFOX scheme has been reported in the literature to cause hyperlipidemia (20).

It is clinically important to prevent hypertriglyceridemia, as this condition accounts for $10 \%$ of pancreatitis cases (9). It is also a common cardiovascular risk factor. Considering that the incidence of cancer is higher in elderly individuals, whose cardiovascular system is fragile, it is predictable that comorbidity of CVD and metabolic disorder (14), which is another reason for more careful use of CAP and monitoring of blood lipids.

We genuinely hope that clinicians notice this not-so-rare side effect, as CAP is so widely used, and it is important to monitor blood lipids (especially TG) over time, especially for those with high-risk factors such as metabolic diseases and ischemic cardiomyopathy.

\section{Acknowledgments}

Funding: None.

\section{Footnote}

Reporting Checklist: The authors have completed the CARE reporting checklist. Available at https://apm.amegroups. com/article/view/10.21037/apm-21-1109/rc

Conflicts of Interest: All authors have completed the ICMJE uniform disclosure form (available at https://apm. amegroups.com/article/view/10.21037/apm-21-1109/coif). The authors have no conflicts of interest to declare.

Ethical Statement: The authors are accountable for all aspects of the work in ensuring that questions related to the accuracy or integrity of any part of the work are appropriately investigated and resolved. All procedures performed in this study were in accordance with the ethical standards of the institutional and/or national research committee(s) and with the Helsinki Declaration (as revised in 2013). Written informed consent was obtained from the patient for publication of this case report and accompanying images. A copy of the written consent is available for review by the editorial office of this journal.

Open Access Statement: This is an Open Access article distributed in accordance with the Creative Commons Attribution-NonCommercial-NoDerivs 4.0 International License (CC BY-NC-ND 4.0), which permits the noncommercial replication and distribution of the article with the strict proviso that no changes or edits are made and the original work is properly cited (including links to both the formal publication through the relevant DOI and the license). See: https://creativecommons.org/licenses/by-nc-nd/4.0/.

\section{References}

1. Blum JL, Jones SE, Buzdar AU, et al. Multicenter phase II study of capecitabine in paclitaxel-refractory metastatic breast cancer. J Clin Oncol 1999;17:485-93.

2. Cassidy J, Clarke S, Díaz-Rubio E, et al. XELOX vs FOLFOX-4 as first-line therapy for metastatic colorectal cancer: NO16966 updated results. Br J Cancer 
2011;105:58-64.

3. Münz C. Latency and lytic replication in EpsteinBarr virus-associated oncogenesis. Nat Rev Microbiol 2019;17:691-700.

4. Südhoff T, Enderle MD, Pahlke M, et al. 5-Fluorouracil induces arterial vasocontractions. Ann Oncol 2004;15:661-4.

5. Peng J, Dong C, Wang C, et al. Cardiotoxicity of 5-fluorouracil and capecitabine in Chinese patients: a prospective study. Cancer Commun (Lond) 2018;38:22.

6. Kato K, Lyon AR, Ghadri JR, et al. Takotsubo syndrome: aetiology, presentation and treatment. Heart 2017;103:1461-9.

7. Naranjo CA, Busto U, Sellers EM, et al. A method for estimating the probability of adverse drug reactions. Clin Pharmacol Ther 1981;30:239-45.

8. Sassolas B, Haddad C, Mockenhaupt M, et al. ALDEN, an algorithm for assessment of drug causality in StevensJohnson Syndrome and toxic epidermal necrolysis: comparison with case-control analysis. Clin Pharmacol Ther 2010;88:60-8.

9. Catapano AL, Graham I, De Backer G, et al. 2016 ESC/ EAS Guidelines for the Management of Dyslipidaemias. Eur Heart J 2016;37:2999-3058.

10. Available oneline: https://www.acc.org/latestin-cardiology/articles/2019/01/11/07/39/ hypertriglyceridemia-management-according-to-the2018-aha-acc-guideline

11. Koutras AK, Habeos IG, Vagenakis AG, et al. Capecitabine-induced hypertriglyceridemia: a report of two cases. Anticancer Res 2006;26:2249-51.

12. Bar-Sela G, Haim N. Uncontrolled hypertriglyceridemia induced by capecitabine: case report and review of the literature. Cancer Chemother Pharmacol 2009;63:779-82.

13. Leung J, Brady JL, Crook MA. The clinical importance of recognizing capecitabine-induced hypertriglyceridemia: A case report and review of the literature. J Clin Lipidol 2018;12:1371-3.

Cite this article as: Zhou W, Ni L, Luo M, Shu X, Cao P, Qiu M. Rare capecitabine-induced acute hypertriglyceridemia with angina: a case report and review of the literature. Ann Palliat Med 2022;11(6):2152-2156. doi: 10.21037/apm-21-1109
14. Seminara P, Losanno T, Emiliani A, et al. Cancer chemotherapy and cardiovascular risks: is capecitabineinduced hypertriglyceridemia a rare adverse effect? Cardiology 2010;116:42-4.

15. Duman BB, Paydas S, Tetiker T, et al. Capecitabineinduced hypertriglyceridemia and hyperglycemia: two cases. Pharmacology 2012;90:212-5.

16. Kurt M, Babaoglu MO, Yasar U, et al. Capecitabineinduced severe hypertriglyceridemia: report of two cases. Ann Pharmacother 2006;40:328-31.

17. Chan HY, Ng CM, Tiu SC, et al. Hypertriglyceridaemiainduced pancreatitis: a contributory role of capecitabine? Hong Kong Med J 2012;18:526-9.

18. Uche A, Vankina R, Gong J, et al. Capecitabine-induced hypertriglyceridemia: a rare but clinically relevant treatment-related adverse event. J Gastrointest Oncol 2018;9:1213-9.

19. Polinder-Bos HA, Kok EE, van de Wiel A, et al. Severe hypertriglyceridaemia associated with the use of capecitabine. Neth J Med 2012;70:104.

20. Michie CO, Sakala M, Rivans I, et al. The frequency and severity of capecitabine-induced hypertriglyceridaemia in routine clinical practice: a prospective study. Br J Cancer 2010;103:617-21.

21. Garg R, Angus E, Fincher S. Capecitabine-induced severe hypertriglyceridaemia and diabetes: a case report and review of the literature. Diabet Med 2009;26:1308-9.

22. Javot L, Spaëth D, Scala-Bertola J, et al. Severe hypertriglyceridaemia during treatment with capecitabine. Br J Cancer 2011;104:1238-9.

23. Han GH, Huang JX. Hypertriglyceridemia and hyperglycemia induced by capecitabine: a report of two cases and review of the literature. J Oncol Pharm Pract 2015;21:380-3.

24. Orphanos GS, Stavrou NG, Picolos MK. Hypertriglyceridemia: An underdiagnosed side effect of Capecitabine chemotherapy. Acta Oncol 2010;49:262-3. 